Bull. Chem. Soc. Ethiop. 2016, 30(1), 137-146.

Printed in Ethiopia

ISSN 1011-3924

DOI: http://dx.doi.org/10.4314/bcse.v30i1.13

(c) 2016 Chemical Society of Ethiopia

\title{
PICOLINIC ACID PROMOTED OXIDATIVE DECARBOXYLATION OF PHENYLSULFINYLACETIC ACID BY Cr(VI)
}

\author{
Perumal Subramaniam $^{1 *}$ and Natesan Thamil Selvi ${ }^{2}$ \\ ${ }^{1}$ Research Department of Chemistry, Aditanar College of Arts and Science, \\ Tiruchendur-628 216, India \\ ${ }^{2}$ Govindammal Aditanar College for Women, Tiruchendur, India
}

(Received August 22, 2013; revised October 29, 2015)

\begin{abstract}
The kinetics and mechanism of picolinic acid promoted reaction of phenylsulfinylacetic acid (PSAA) with $\mathrm{Cr}(\mathrm{VI})$ was carried out in aqueous acetonitrile medium under pseudo first order conditions. The reaction follows Michaelis-Menten type of kinetics with respect to PSAA. The catalytic activity by picolinic acid can be interpreted on the basis of the formation of a highly active oxidizing species, $\mathrm{Cr}(\mathrm{VI})-\mathrm{PA}$ complex. The mechanism involves the formation of a termolecular complex, Cr(VI)-PA-PSAA by the nucleophilic attack of the sulfur atom of PSAA on chromium of $\mathrm{Cr}(\mathrm{VI})-\mathrm{PA}$ complex in an equilibrium step followed by ligand coupling in a slow step. Electron releasing substituents in the phenyl ring of PSAA accelerate while electron withdrawing groups retard the reaction rate. The overall rate constants for the para- and meta-substituted PSAAs are found to correlate excellently with Hammett $\sigma$ constants with a very low reaction constant, $\rho$.
\end{abstract}

KEY WORDS: Phenylsulfinylacetic acid, Cr(VI), Picolinic acid, Oxidative decarboxylation, Substituent effect, Catalysis

\section{INTRODUCTION}

$\mathrm{Cr}(\mathrm{VI})$ is an excellent oxidizing agent for both preparative and analytical purposes. During oxidation reactions, the main co-ordination site of $\mathrm{Cr}$ binding involves alcoholato, carboxylato and thiolato groups $[1,2]$. The pyridine bases and other ligands containing hetero nitrogen atoms were found to facilitate the $\mathrm{Cr}(\mathrm{VI})$ oxidation reactions to a greater extent and the various chelating agents explored for this purpose are picolinic acid, pyridine-2,6-dicarboxylic acid, 2,2'-bipyridyl, 1,10-phenanthroline, EDTA, etc. In the presence of chelating agents the redox activity of $\mathrm{Cr}(\mathrm{VI})$ has been found to change drastically. The complexing agents influence the nature of $\mathrm{Cr}(\mathrm{VI})$ species in the reaction mixture and even affect the mechanism of $\mathrm{Cr}(\mathrm{VI})$ oxidation in some cases.

Picolinic acid (PA), an endogenous metabolite of L-tryptophan that has been detected in a variety of biological media including cell culture supernatants, blood serum [3], cerebrospinal fluid [4], pancreatic juice and intestinal homogenates [5], possesses a wide range of neuroprotective, immunological and anti-proliferative effects [6]. PA is an efficient chelating agent which forms mono and bis complexes through pyridine nitrogen and carboxylate oxygen [7] with a range of metals including $\mathrm{Tl}$, Mo and $\mathrm{W}[8,9]$. Capitalizing on its chelation properties, PA-metal complexes are widely used as means of introducing bioactive metals into biological systems $[10,11]$. In the case of PA catalyzed $\mathrm{Cr}(\mathrm{VI})$ oxidation reactions, $\mathrm{PA}$ is not itself oxidized but lost during the reaction due to the formation of an inert $\mathrm{Cr}$ (III)-PA complex. Thus PA is not a true catalyst and it is better described as a promoter. Picolinic acid promoted $\mathrm{Cr}$ (VI) oxidation of several organic substrates [12-16] including organic sulfur compounds [12, 17-19] have been extensively studied. The catalytic effect was attributed to the activation of oxidizing species of chromium through a precursor complex formation.

Though phenylsulfinylacetic acid (PSAA) is a versatile compound finding utility in pharmaceutical and synthetic fields [20-26], literature survey clearly reveals that there is no

*Corresponding author. E-mail: subramaniam.perumal@gmail.com 
systematic mechanistic study on the oxidation of PSAA except our recent publications [27-31]. Hence, in continuation of our work it is decided to carry out a systematic investigation on the PA promoted $\mathrm{Cr}(\mathrm{VI})$ reaction with PSAA with a view to proposing a suitable mechanistic path.

\section{EXPERIMENTAL}

Phenylsulfinylacetic acid and several para- and meta-substituted PSAAs were synthesized from the corresponding phenylthioacetic acids via controlled oxidation using equimolar amount of $\mathrm{H}_{2} \mathrm{O}_{2}$ [32] and recrystallised from suitable solvents [33]. The purity of the samples was checked by LCMS and comparing their melting points with the literature values [33]. Potassium dichromate (Merck), sodium perchlorate (Merck), $\mathrm{HClO}_{4}$ (Merck) and picolinic acid (SDS) were of AnalaR grade and were used as received. The solvents, acetonitrile and water were purified by literature methods.

\section{Kinetic measurements}

The kinetic measurements were performed by monitoring absorbance changes using Elico Double beam UV-vis Bio-spectrophotometer with an inbuilt thermostat, under pseudo first order conditions by maintaining [PSAA] » $[\mathrm{Cr}(\mathrm{VI})]$ in $40 \%$ acetonitrile $-60 \%$ water $(\mathrm{v} / \mathrm{v})$ medium in the presence of PA. The disappearance of $\mathrm{Cr}(\mathrm{VI})$ was followed at $351 \mathrm{~nm}$ until $75 \% \mathrm{of} \mathrm{Cr}(\mathrm{VI})$ was consumed and the spectral changes observed at different time intervals during the reaction are given in Figure 1. Sodium perchlorate and perchloric acid were used to maintain the ionic strength and acidity of the medium, respectively.

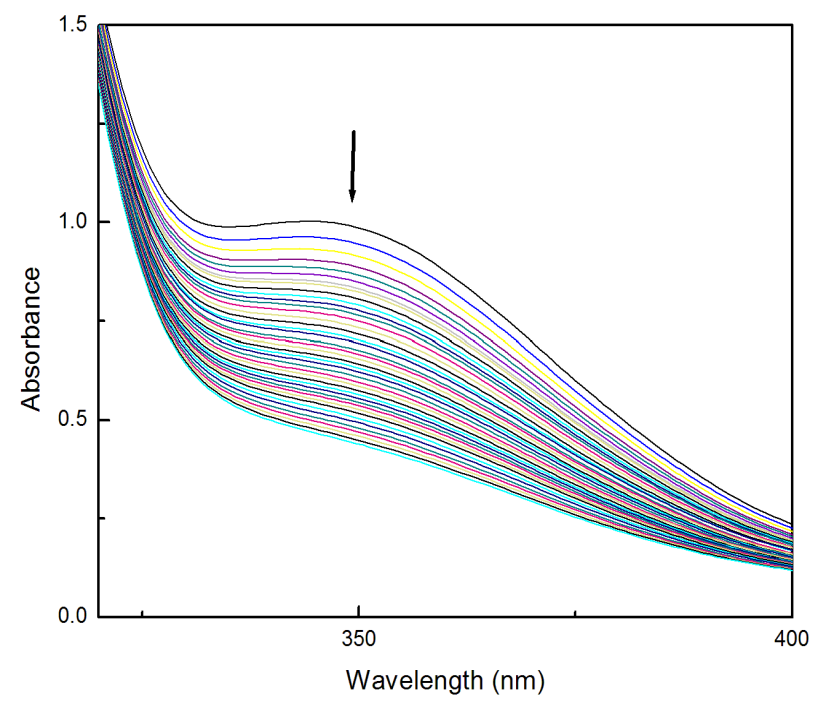

Figure 1. UV-visible spectra for the kinetic run. [PSAA] $=5.0 \times 10^{-2} \mathrm{~mol} \mathrm{dm}^{-3} ;[\mathrm{Cr}(\mathrm{VI})]=5.0 \mathrm{x}$ $10^{-4} \mathrm{~mol} \mathrm{dm}^{-3} ;[\mathrm{PA}]=0.3 \mathrm{~mol} \mathrm{dm}^{-3} ;\left[\mathrm{H}^{+}\right]=0.75 \mathrm{~mol} \mathrm{dm}^{-3}$.

The pseudo-first order rate constant $\left(\mathrm{k}_{1}\right)$ for each kinetic run was evaluated from the slope of $\log$ OD vs time by the method of least squares. The precision of $\mathrm{k}$ values is given in terms of $95 \%$ confidence limits of Student's t test. 


\section{Product analysis}

The reaction mixture with excess of [Cr(VI)] over [PSAA] was kept for 48 hours to ensure completion of the reaction and the solution was then extracted with ether. The ether layer was collected, dried over anhydrous sodium sulfate and the solvent was removed by evaporation. The GC-MS chromatogram of the product (Figure 2) with 100\% abundance eluted at a retention time of $12.47 \mathrm{AV}$ gave the base parent peak at $\mathrm{m} / \mathrm{z}=156$. The value shows the molar mass of methyl phenyl sulfone. The peak position and fragmentation pattern exactly matches with that of the reference, methyl phenyl sulfone (Figure 2 - inset). This is further confirmed by IR spectroscopy (Figure 3) which shows strong bands at $1148 \mathrm{~cm}^{-1}$ and $1290 \mathrm{~cm}^{-1}$ characteristic of symmetric and asymmetric stretching respectively of $>\mathrm{SO}_{2}$ group [34, 35]. The other characteristic absorption frequencies $\left(\mathrm{cm}^{-1}\right)$ of methyl phenyl sulfone are $\mathrm{sp}^{2} \mathrm{C}-\mathrm{H}$ stretch (3024), $\mathrm{sp}^{2} \mathrm{C}-\mathrm{H}$ bend (744), $\mathrm{sp}^{3} \mathrm{C}-\mathrm{H}$ stretch (2922), $\mathrm{sp}^{3} \mathrm{C}-\mathrm{H}$ bend (1451), aromatic $\mathrm{C}=\mathrm{C}$ (1647) and aromatic C-C stretch (1402).

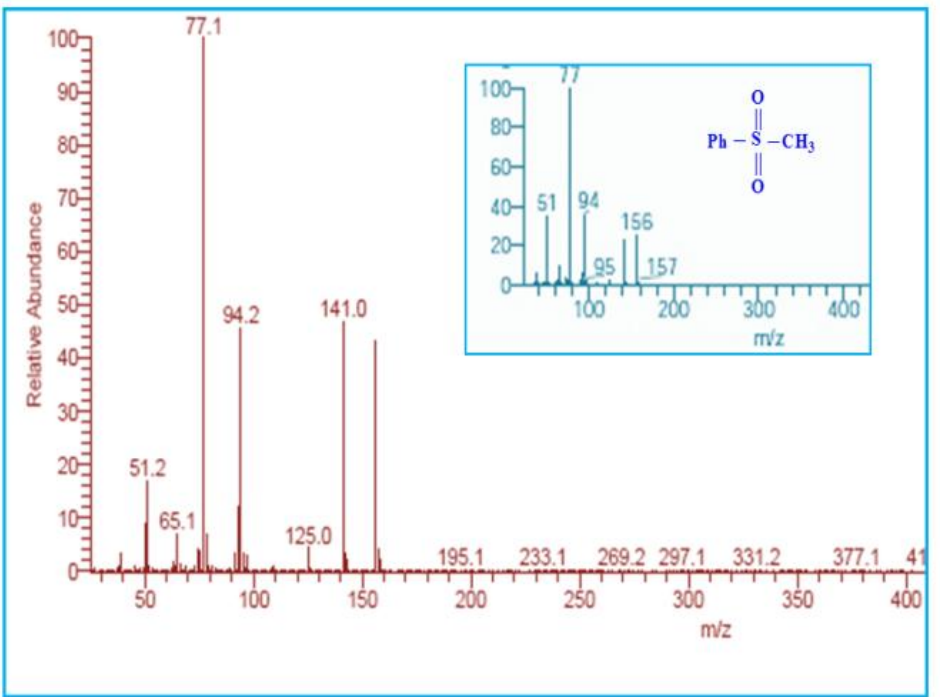

Figure 2. GC-MS spectrogram of the product.

The UV-visible spectroscopy aids in the determination of the final fate of $\mathrm{Cr}(\mathrm{VI})$ in the reaction mixture. The UV-visible spectra of Cr(III) ion shows two peaks at $421 \mathrm{~nm}$ and $592 \mathrm{~nm}$ which are attributed to the octahedral transitions, ${ }^{4} \mathrm{~A}_{2 \mathrm{~g}}(\mathrm{~F}) \rightarrow{ }^{4} \mathrm{~T}_{1 \mathrm{~g}}(\mathrm{~F})$ and ${ }^{4} \mathrm{~A}_{2 \mathrm{~g}}(\mathrm{~F}) \rightarrow{ }^{4} \mathrm{~T}_{2 \mathrm{~g}}(\mathrm{~F})[36-$ 38] whereas the spectrum of the product mixture exhibits two peaks at $408 \mathrm{~nm}$ and $542 \mathrm{~nm}$ (Figure 4). This clearly demonstrates that $\mathrm{Cr}(\mathrm{VI})$ is reduced to $\mathrm{Cr}(\mathrm{III})$ ion but the blue shift observed in $\lambda_{\max }$ values for the product mixture is due to existence of $\mathrm{Cr}$ (III) in the form of complex, probably the $\mathrm{Cr}(\mathrm{III})-\mathrm{PA}$ complex as reported in the PA catalysed $\mathrm{Cr}(\mathrm{VI})$ oxidation reactions [12-14]. 


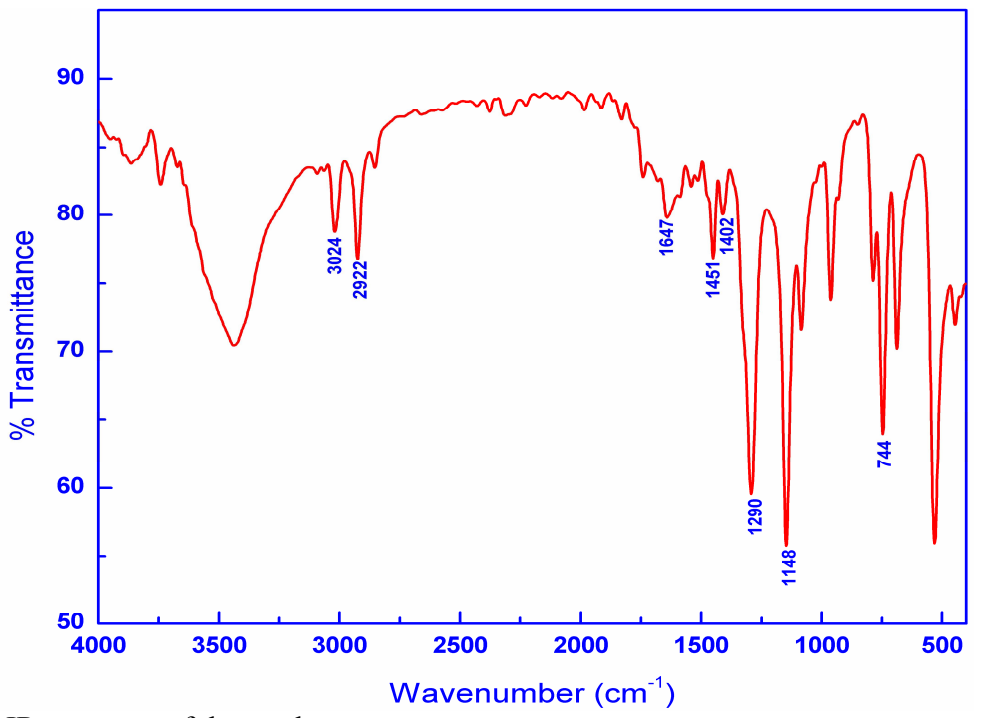

Figure 3. IR spectrum of the product.

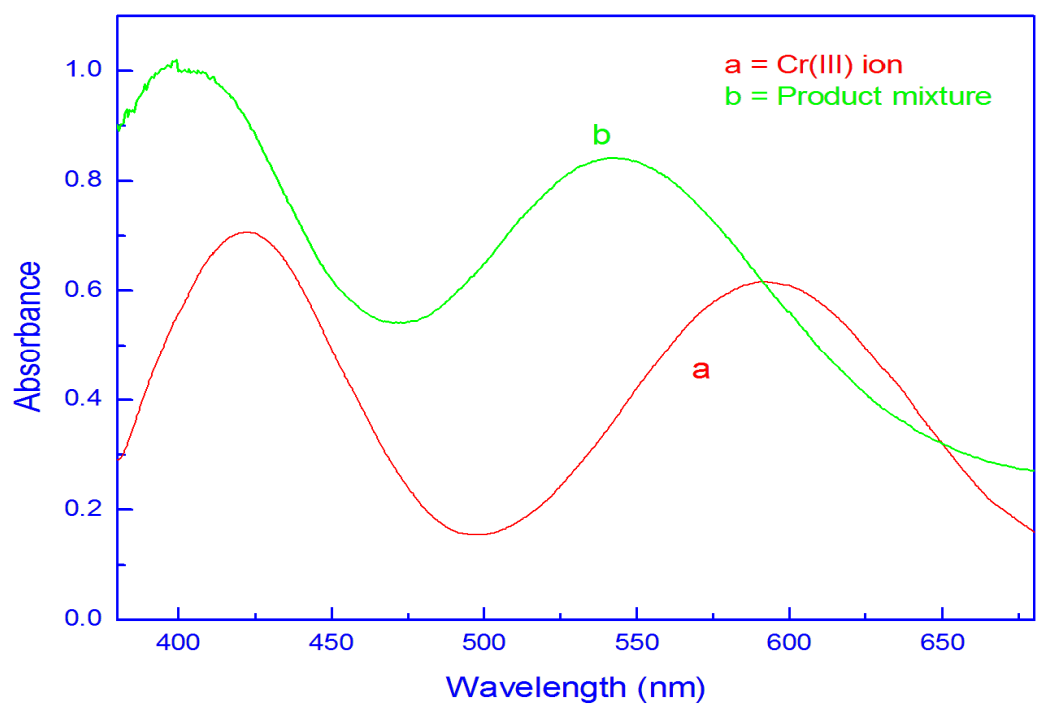

Figure 4. UV-visible spectra of $\mathrm{Cr}(\mathrm{III})$ ion and product mixture.

\section{RESULTS}

That the reaction exhibits first order dependence on $\mathrm{Cr}(\mathrm{VI})$ in the presence of $\mathrm{PA}$ is obvious from the linear $\log$ OD vs time plots even upto $75 \%$ completion of the reaction and from constant $\mathrm{k}_{1}$ values obtained at different initial [Cr(VI)] (Table 1). The second order rate constants obtained using the relation $\mathrm{k}_{2}=\mathrm{k}_{1} /[\mathrm{PSAA}]$ are not found to be constant. Further, the 
double logarithmic plot of $\mathrm{k}_{1}$ vs [PSAA] is linear $(\mathrm{r}=0.999)$ with slope $=0.61 \pm 0.01$ indicating that the reaction is of fractional order $(0.61)$ with respect to PSAA. Hence, the overall rate of the reaction, $\mathrm{k}_{\mathrm{ov}}$ is obtained from the relation, $\mathrm{k}_{\mathrm{ov}}=\mathrm{k}_{1} /$ [PSAA] $^{0.61}$. The plot of $\mathrm{k}_{1}^{-1}$ vs [PSAA $]^{-1}$ is linear $(r=0.998)$ with an intercept on the rate axis indicating the Michaelis-Menten dependence on PSAA [39].

Table 1. Pseudo-first order and overall rate constants for the reaction.

\begin{tabular}{|c|c|c|c|}
\hline $10^{2}[\mathrm{PSAA}]\left(\mathrm{mol} \mathrm{dm}^{-3}\right)$ & $10^{4}[\mathrm{Cr}(\mathrm{VI})]\left(\mathrm{mol} \mathrm{dm}^{-3}\right)$ & $10^{4} \mathrm{k}_{1}\left(\mathrm{~s}^{-1}\right)$ & $10^{3} \mathrm{k}_{\mathrm{ov}}\left(\mathrm{dm}^{3} \mathrm{~mol}^{-1}\right)^{0.61} \mathrm{~s}^{-1}$ \\
\hline 1.0 & 5.0 & $3.70 \pm 0.13$ & $6.15 \pm 0.13$ \\
\hline 3.0 & 5.0 & $7.65 \pm 0.07$ & $6.49 \pm 0.02$ \\
\hline 5.0 & 5.0 & $10.0 \pm 0.11$ & $6.22 \pm 0.02$ \\
\hline 7.0 & 5.0 & $12.3 \pm 0.02$ & $6.21 \pm 0.01$ \\
\hline 10 & 5.0 & $15.3 \pm 0.05$ & $6.23 \pm 0.01$ \\
\hline 5.0 & 1.0 & $9.30 \pm 0.46$ & $5.78 \pm 0.09$ \\
\hline 5.0 & 3.0 & $9.96 \pm 0.03$ & $6.19 \pm 0.01$ \\
\hline 5.0 & 7.0 & $9.54 \pm 0.39$ & $5.93 \pm 0.08$ \\
\hline
\end{tabular}

$[\mathrm{PA}]=0.3 \mathrm{~mol} \mathrm{dm}^{-3} ;\left[\mathrm{H}^{+}\right]=0.75 \mathrm{~mol} \mathrm{dm}^{-3} ; \mathrm{I}=0.80 \mathrm{~mol} \mathrm{dm}^{-3} ;$ solvent $=40 \%$ acetonitrile $-60 \%$ water $(\mathrm{v} / \mathrm{v}) ; \mathrm{T}=$ $30^{\circ} \mathrm{C}$.

The reaction is greatly influenced by the acidity of the medium (Table 2) and the order in $\left[\mathrm{H}^{+}\right]$is unity which is evident from the linear log-log plot of $\mathrm{k}_{1}$ against $\left[\mathrm{H}^{+}\right](\mathrm{r}=0.999)$ with slope $=1.0 \pm 0.02$. The rate increases significantly with increasing acetonitrile content of the medium (Table 2) suggesting a facile reactivity in a medium of low dielectric constant.

The effect of picolinic acid on the reaction rate indicates a slight increase in rate with increase in the concentration of PA initially up to $0.15 \mathrm{~mol} \mathrm{dm}^{-3}$ and after that an appreciable linear enhancement of rate is noted with increase in [PA]. The effect of PA is depicted in Table 2. The double inverse plot of $\mathrm{k}_{1}$ vs [PA] in the $0.15-0.5 \mathrm{~mol} \mathrm{dm}^{-3}$ range shows an intercept in the rate axis which confirms the reversible complex formation of PA with any one of the reactants.

Table 2. Effect of $\left[\mathrm{H}^{+}\right]$, $[\mathrm{PA}]$, solvent composition and temperature on rate.

\begin{tabular}{|c|c|c|c|c|c|c|c|}
\hline $\begin{array}{c}10^{2} \mathrm{PA} \\
\left(\mathrm{mol} \mathrm{dm}^{-3}\right)\end{array}$ & $\begin{array}{c}10^{4} \mathrm{k}_{1}{ }^{\mathrm{a}} \\
\left(\mathrm{s}^{-1}\right)\end{array}$ & $\begin{array}{c}10^{1}\left[\mathrm{H}^{+}\right] \\
\left(\mathrm{mol} \mathrm{dm}^{-3}\right)\end{array}$ & $\begin{array}{c}10^{4} \mathrm{k}_{1}{ }^{\mathrm{b}} \\
\left(\mathrm{s}^{-1}\right)\end{array}$ & $\begin{array}{c}\mathrm{CH}_{3} \mathrm{CN}-\mathrm{H}_{2} \mathrm{O} \\
(\%, \mathrm{~V} / \mathrm{v})\end{array}$ & $\begin{array}{c}10^{4} \mathrm{k}_{1}{ }^{\mathrm{c}} \\
\left(\mathrm{s}^{-1}\right)\end{array}$ & $\begin{array}{c}\mathrm{T} \\
\left({ }^{\circ} \mathrm{C}\right)\end{array}$ & $\begin{array}{c}10^{3} \mathrm{k}_{\mathrm{ov}} \mathrm{d}^{\mathrm{d}} \\
\left(\mathrm{dm}^{3} \mathrm{~mol}^{-1}\right)^{0.61} \mathrm{~s}^{-1}\end{array}$ \\
\hline 0 & $6.49 \pm 0.25$ & 3.0 & $4.10 \pm 0.13$ & $20-40$ & $8.23 \pm 0.12$ & 20 & $2.75 \pm 0.09$ \\
\hline 0.50 & $6.94 \pm 0.10$ & 5.0 & $6.98 \pm 0.12$ & $40-60$ & $10.0 \pm 0.11$ & 25 & $4.12 \pm 0.01$ \\
\hline 5.0 & $7.92 \pm 0.11$ & 7.5 & $10.2 \pm 0.09$ & $60-80$ & $12.7 \pm 0.08$ & 30 & $6.22 \pm 0.12$ \\
\hline 8.0 & $7.93 \pm 0.11$ & 9.0 & $12.3 \pm 0.05$ & $80-20$ & $16.1 \pm 0.11$ & 35 & $8.23 \pm 0.17$ \\
\hline 15 & $7.93 \pm 0.03$ & 10 & $14.0 \pm 0.52$ & & & & \\
\hline 25 & $9.97 \pm 0.06$ & & & & & & \\
\hline 30 & $10.0 \pm 0.11$ & & & & & & \\
\hline 40 & $12.1 \pm 0.04$ & & & & & & \\
\hline 50 & $13.8 \pm 0.06$ & & & & & & \\
\hline
\end{tabular}

$[$ PSAA $]=5.0 \times 10^{-2} \mathrm{~mol} \mathrm{dm}^{-3} ;[\mathrm{Cr}(\mathrm{VI})]=5.0 \times 10^{-4} \mathrm{~mol} \mathrm{dm}^{-3} ;\left[\mathrm{H}^{+}\right]=0.75 \mathrm{~mol} \mathrm{dm}^{-3} ; \mathrm{CH}_{3} \mathrm{CN}_{-} \mathrm{H}_{2} \mathrm{O}(40-60 \%, \mathrm{v} / \mathrm{v})$; a,c,d $\mathrm{I}=0.8 \mathrm{~mol} \mathrm{dm}^{-3} ;{ }^{\mathrm{b}} \mathrm{I}=1.1 \mathrm{~mol} \mathrm{dm}^{-3}$.

The reaction is carried out at four different temperatures viz., 20, 25, 30 and $35^{\circ} \mathrm{C}$ and the $\mathrm{k}_{\mathrm{ov}}$ values are presented in Table 2 . The thermodynamic parameters are evaluated from the intercept and slope of the Eyring plot of $\log \mathrm{k}_{\mathrm{ov}} / \mathrm{T}$ vs $1 / \mathrm{T}$. The entropy of activation, $\Delta \mathrm{S}^{\neq}$and enthalpy of activation, $\Delta \mathrm{H}^{\neq}$calculated for the PA promoted $\mathrm{Cr}(\mathrm{VI})$ reaction of PSAA are $-112.38 \pm 6.6 \mathrm{~J} \mathrm{~K}^{-1} \mathrm{~mol}^{-1}$ and $53.17 \pm 1.9 \mathrm{KJ} \mathrm{mol}^{-1}$ respectively whereas for the uncatalysed reaction the values are $-24.49 \pm 0.09 \mathrm{~J} \mathrm{~K}^{-1} \mathrm{~mol}^{-1}$ and $75.58 \pm 2.5 \mathrm{KJ} \mathrm{mol}^{-1}$ respectively which follow the trend expected for the catalysed reaction. 
As the study of substituent effect gives positive evidences on the nature of transition state and mechanism, the effect of substituents on the PA catalysed oxidative decarboxylation rate is carried out with several para- and meta- substituted phenylsulfinylacetic acids at $30^{\circ} \mathrm{C}$. The plot of $\log \mathrm{k}_{\mathrm{ov}}$ vs Hammett constants, $\sigma$ gives an excellent correlation (Figure 5, $\mathrm{r}=0.997$ ) with low negative reaction constant, $\rho(\rho=-0.322 \pm 0.01)$.

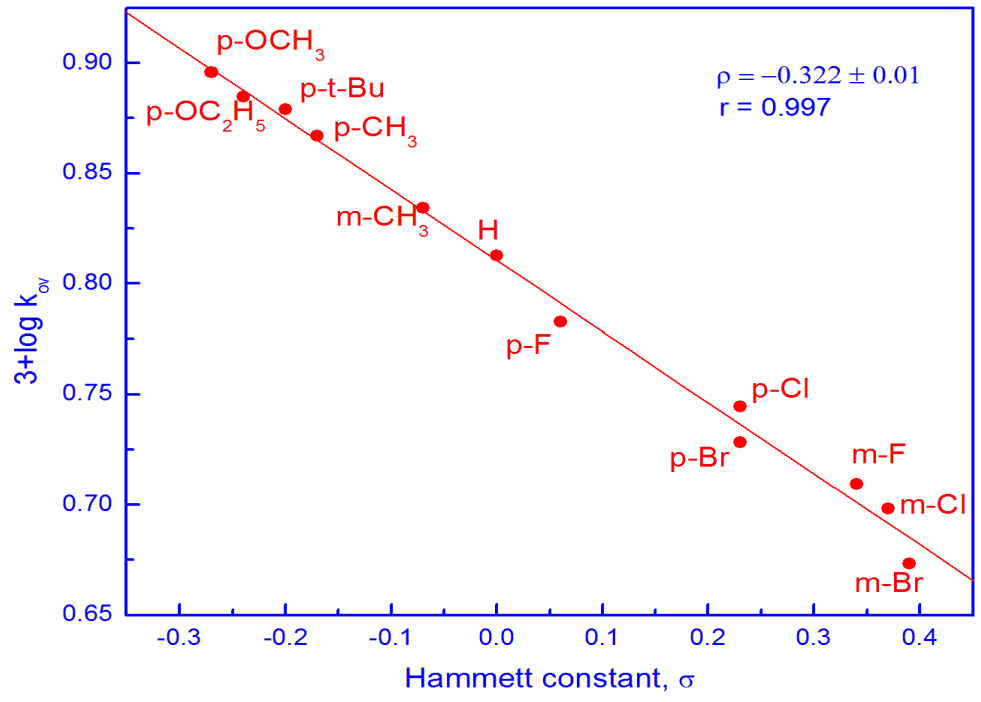

Figure 5. Hammett plot at $30^{\circ} \mathrm{C}$.

\section{DISCUSSION}

The active oxidizing species involved in the reaction may be $\mathrm{Cr}(\mathrm{VI})$ itself or $\mathrm{Cr}(\mathrm{V})$ formed as a result of one-electron transfer or $\mathrm{Cr}(\mathrm{IV})$ due to two-electron transfer. The absence of absorption at $750 \mathrm{~nm}$, where $\mathrm{Cr}(\mathrm{V})$ is the only absorbing species [40], rules out the involvement of $\mathrm{Cr}(\mathrm{V})$ as an active species. Besides, the insensitivity of rate to added radical scavenger, acrylamide, clearly rules out the single-electron transfer mechanism and hence the involvement of $\mathrm{Cr}(\mathrm{V})$ species in the reaction mechanism. The added $\mathrm{Mn}^{2+}$ ion, scavenger for $\mathrm{Cr}(\mathrm{IV})$, has failed to produce any noticeable effect on the reaction rate ruling out the participation of $\mathrm{Cr}(\mathrm{IV})$ as the active species. Thus, the active species in this reaction is $\mathrm{Cr}(\mathrm{VI})$ itself, which exists in aqueous acidic solution in a variety of forms such as $\mathrm{CrO}_{4}{ }^{2-}, \mathrm{HCrO}_{4}{ }_{4}^{-}$and $\mathrm{Cr}_{2} \mathrm{O}_{7}{ }^{2-}$ besides other protonated forms like $\mathrm{HCrO}_{3}{ }^{+}, \mathrm{H}_{2} \mathrm{CrO}_{4}, \mathrm{H}_{2} \mathrm{Cr}_{2} \mathrm{O}_{7}$ and $\mathrm{HCr}_{2} \mathrm{O}_{7}^{-}$depending on $[\mathrm{Cr}(\mathrm{VI})]$ and the $\mathrm{pH}$ of the medium [41-44]. If the concentration is above $0.05 \mathrm{~mol} \mathrm{dm}^{-3}, \mathrm{Cr}(\mathrm{VI})$ mainly exists as dimeric forms while at lower concentrations it exists predominantly in monomeric forms $[41,45,46]$. At lower concentrations of $\mathrm{H}^{+}, \mathrm{HCrO}_{4}^{-}$is the main species whereas $\mathrm{HCrO}_{3}{ }^{+}$is the major moiety at higher $\left[\mathrm{H}^{+}\right][45,47,48]$. Thus, under the present experimental conditions of high $\left[\mathrm{H}^{+}\right]$and low $[\mathrm{Cr}(\mathrm{VI})], \mathrm{HCrO}_{3}{ }^{+}$species is assumed to be the active form of $\mathrm{Cr}(\mathrm{VI})$. The first order dependence of the reaction rate on $\left[\mathrm{H}^{+}\right]$and $[\mathrm{Cr}(\mathrm{VI})]$ are in agreement with the existence of $\mathrm{HCrO}_{3}^{+}$species.

In earlier reports $[12,14,49]$ it has been observed that the redox potential of $\mathrm{Cr}(\mathrm{VI})$ increases in the presence of chelating agents and believed that $\mathrm{Cr}(\mathrm{VI})$ forms complexes with the chelating agents. Thus in the present case, the increase in reaction rate with increase in [PA] may be attributed to the formation of a bimolecular cyclic complex $\left(\mathrm{C}_{1}\right.$, Scheme 1) between $\mathrm{Cr}(\mathrm{VI})$ and PA which is assumed to be the kinetically active oxidizing species [12, 17-19]. 


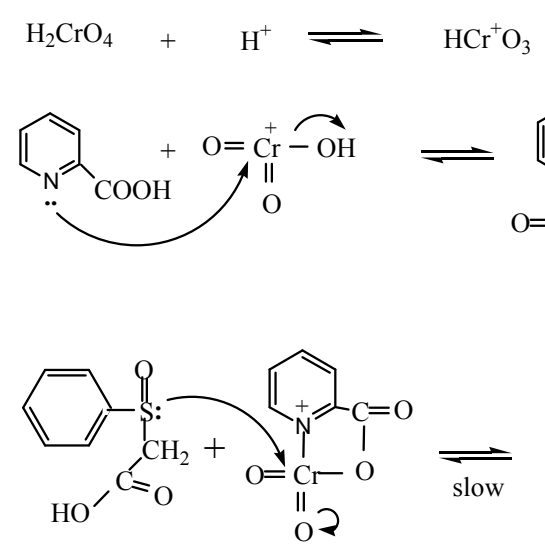

$\left(C_{1}\right)$

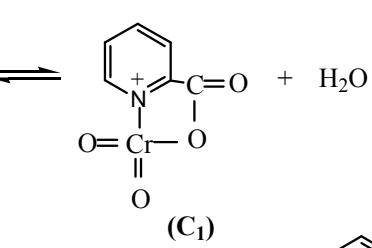

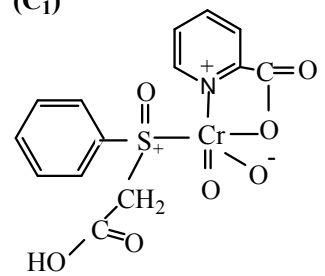

$\left(\mathrm{C}_{2}\right)$

Scheme 1

The spectral evidence for the formation of $\mathrm{Cr}(\mathrm{VI})-\mathrm{PA}$ complex is obtained from the hyperchromic shift and broadening of the UV absorption peak at $263 \mathrm{~nm}$ after the addition of PA to $\mathrm{Cr}(\mathrm{VI})$ (Figure 6). 


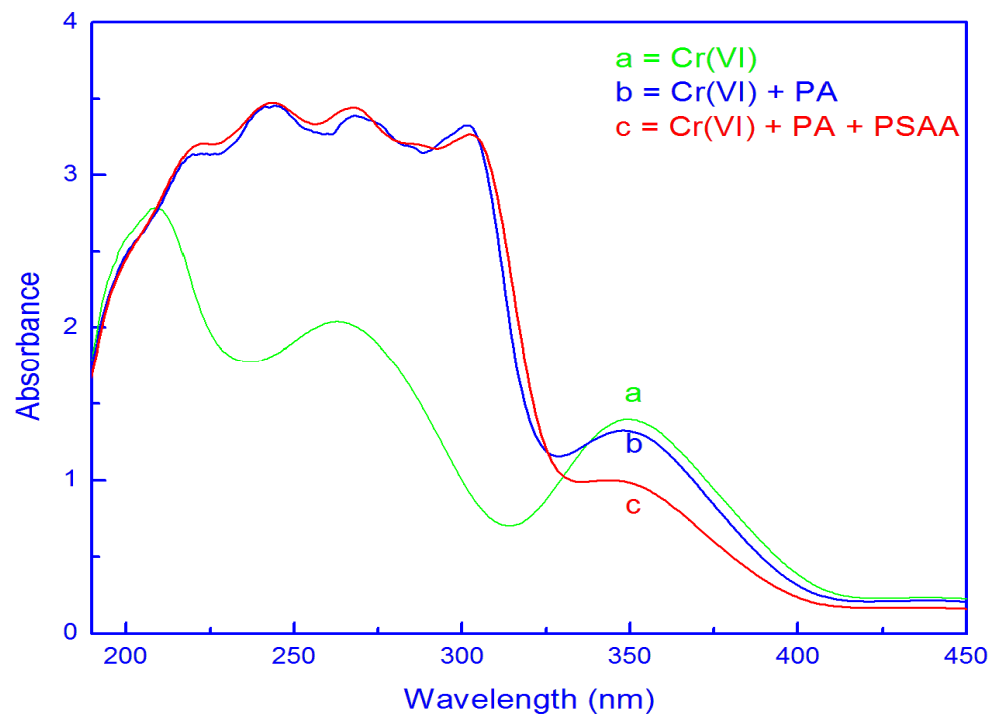

Figure 6. UV-vis absorption spectra. [PSAA] $=5.0 \times 10^{-2} \mathrm{~mol} \mathrm{dm}^{-3} ;[\mathrm{Cr}(\mathrm{VI})]=5.0 \times 10^{-4} \mathrm{~mol}$ $\mathrm{dm}^{-3} ;[\mathrm{PA}]=0.3 \mathrm{~mol} \mathrm{dm}^{-3} ;\left[\mathrm{H}^{+}\right]=0.75 \mathrm{~mol} \mathrm{dm}^{-3}$.

The high reactivity in the presence of PA, confirms that the cationic $\mathrm{Cr}(\mathrm{VI})-\mathrm{PA}$ complex $\left(\mathrm{C}_{1}\right)$ is a more efficient electrophile than $\mathrm{HCrO}_{3}{ }^{+}$itself. The involvement of positive active species in the reaction is proved from the study of dielectric constant of the medium, i.e. a positive slope is obtained when $\log \mathrm{k}_{1}$ is plotted against $1 /$ dielectric constant of the medium. The appreciably high value of Michaelis constant, $\mathrm{K}_{\mathrm{m}}=0.204 \mathrm{~mol} \mathrm{dm}^{-3}$, obtained from the plot of $1 / \mathrm{k}_{1}$ vs $1 /[\mathrm{PA}]$ in the range $0.15-0.5 \mathrm{~mol} \mathrm{dm}^{-3}$ illustrate that only weak binding exists between $\mathrm{PA}$ and $\mathrm{Cr}(\mathrm{VI})$ during the formation of $\mathrm{Cr}(\mathrm{VI})-\mathrm{PA}$ complex.

The chromium atom of $\mathrm{Cr}(\mathrm{VI})-\mathrm{PA}$ complex, $\mathrm{C}_{1}$ then receives a nucleophilic attack by the sulfur atom of PSAA to form a termolecular complex, $\mathrm{C}_{2}$ in a slow step. As the reaction has a non-integral kinetic order for PSAA it is reasonable to envisage that the reaction follows Michaelis-Menten kinetics:

$1 / \mathrm{k}_{1}=1 / \mathrm{k}+\mathrm{K}_{\mathrm{m}} / \mathrm{k}[\mathrm{PSAA}]$

By applying Michaelis-Menten kinetics, the values of $\mathrm{k}$ and $\mathrm{K}_{\mathrm{m}}$ were evaluated from the slope and intercept of the double inverse plot of $\mathrm{k}_{1}$ against [PSAA]. The values of $\mathrm{k}$ and $\mathrm{K}_{\mathrm{m}}$ obtained are $2.04 \times 10^{-3} \mathrm{~s}^{-1}$ and $4.54 \times 10^{-2} \mathrm{~mol} \mathrm{dm}^{-3}$. The nature of binding of PSAA with the active species is found to be moderately high as inferred from the low $\mathrm{K}_{\mathrm{m}}$ value. The spectral evidence for the formation of termolecular complex is obtained from the noticeable hypochromic shift at $351 \mathrm{~nm}$ (Figure 7c) in the UV-visible spectrum of the reaction mixture containing PSAA.

As a result of nucleophilic attack of PSAA on $\mathrm{C}_{1}$, a positive charge is developed on the sulfur atom of PSAA in the intermediate complex $\mathrm{C}_{2}$. The trend of the reaction with different substituents indicates that the electron releasing substituents in the para- and meta- positions accelerate the reaction whereas electron withdrawing groups retard the reaction rate. This can be explained on the basis of stabilization of the positive sulfur centre in complex $\mathrm{C}_{2}$ by electron releasing substituents and destabilization by electron withdrawing substituents. 
The ternary complex then undergoes ligand coupling in a subsequent step to form the intermediate, $\mathrm{C}_{3}$. The observed low negative reaction constant, $\rho$ may be visualized due to the neutralization of positive charge on sulfur atom as a result of ligand coupling with oxygen atom. Such a ligand coupling pathway has already been suggested by the researchers in the PA catalysed $\mathrm{Cr}(\mathrm{VI})$ oxidation of organic sulfur compounds $[12,50]$. The intermediate, $\mathrm{C}_{3}$ then cleaves at $\alpha-\beta$ position to eliminate $\mathrm{CO}_{2}$ followed by oxygen atom transfer to sulfur in fast steps leading to the formation of the product, methylphenyl sulfone. Thus, $\mathrm{Cr}$ (IV)-PA species is formed as a result of two electron transfer which participates in the faster steps with $\mathrm{Cr}(\mathrm{VI})$ to give $\mathrm{Cr}(\mathrm{V})$ [51] and consequently, $\mathrm{Cr}(\mathrm{V})$ oxidizes another PSAA molecule and itself gets reduced to $\mathrm{Cr}(\mathrm{III})-\mathrm{PA}$ species. The $\mathrm{Cr}(\mathrm{V})-\mathrm{Cr}(\mathrm{III})$ couple has a potential of $1.75 \mathrm{~V}$, which would enable the rapid conversion of $\mathrm{Cr}(\mathrm{V})$ to $\mathrm{Cr}(\mathrm{III})$ after the reaction with the substrate [52].

\section{CONCLUSION}

The observed spectral changes in the picolinic acid promoted reaction of phenylsulfinylacetic acid (PSAA) with $\mathrm{Cr}(\mathrm{VI})$ in aqueous acetonitrile media evidence the formation of $\mathrm{Cr}(\mathrm{VI})-\mathrm{PA}$ complex and the termolecular complex formed between $\mathrm{Cr}(\mathrm{VI})$, PA and PSAA. The reaction follows Michaelis-Menten kinetics with respect to PSAA. The ternary complex then undergoes ligand coupling followed by several fast steps to form the products. The trend of the reaction with different meta- and para-substituted PSAAs indicates that the electron releasing substituents accelerate the reaction whereas electron withdrawing groups retard the reaction rate.

\section{REFERENCES}

1. Codd, R.; Dillon, C.T.; Levina, A.; Lay, P.A. Coord. Chem. Rev. 2001, 216, 537.

2. Cieslak-Golonka, M. Polyhedron 1996, 15, 3667.

3. Dazzi, C.; Candiano, G.; Massazza, S.; Ponzetto, A.; Varesio, L. J. Chromatogr. 2001, 751, 61.

4. Coggan, S.E.; Smythe, G.A.; Bilgin, A.; Grant, R.S. J. Neurochem. 2009, 8, 1220.

5. Grant, R.S.; Coggan, S.E.; Smythe, G.A. Int. J. Tryptophan. Res. 2009, $2,71$.

6. Bosco, M.C.; Rapisarda, A.; Massazza, S.; Melillo, G.; Toung, H.; Varesio, L. J. Immunol. 2000, 164, 3283.

7. Erzsebet, K.; Eugenio, G.; Giovanni, M.; Tamas, K.; Hiromu, S. J. Inorg. Biochem. 2000, 78, 97.

8. Casas, J.S.; Castellano, E.E.; Ellena, J.; Garcia-Tasende, M.S.; Sanchez, A.; Sordo, J.; Toma, M. Polyhedron 2008, 27, 1296.

9. Janusz, S.; Agnieszka, M.; Dariusz, M.; John, F. Inorg. Chim. Acta 2005, 358, 1749.

10. Yasumatsu, N.; Yoshikawa, Y.; Adachi, Y.; Sakurai, H. Bioorg. Med. Chem. 2007, 15, 4917.

11. Broadhurst, C.L.; Domenico, P. Diabetes. Technol. Ther. 2006, 8, 677.

12. Das, A.K.; Mondal, S.K.; Kar, D. Das. M. Int. J. Chem. Kinet. 2001, 33, 173.

13. Meenakshisudnaram, S. Sarathi, N. Trans. Met. Chem. 2006, 31, 569.

14. Das, A.K.; Roy, A.; Saha, B.; Mohanty, R.K.; Das, M. J. Phys. Org. Chem. 2001, 14, 333.

15. Meenakshisundaram, S.; Sarathi, N. Indian J. Chem. 2007, 46A, 1778.

16. Das, A.K. Coord. Chem. Rev. 2004, 248, 81.

17. Srinivasan, C.; Rajagopal, S.; Chellamani, A. J. Chem. Soc. Perkin. Trans. II 1990, 1839.

18. Das, A.K.; Mondal, S.K.; Kar, D.; Das, M. J. Chem. Res. (S) 1998, 574.

19. Manohar, T.C.; Rajkumar, M.; Rajagopal, S. Trans. Met. Chem. 2006, 31, 549.

20. Sumangala, V.; Boja, P.; Chidananda, N.; Arulmoli, T.; Shalini, S. J. Chem. Pharm. Res. 2012, 4, 1661. 
21. Gogan, N.J.; Newlands, M.J.; Tan, Beck-Yu. Can. J. Chem. 1972, 50, 3203.

22. Janczewski, M.; Najda, T.; Jablonska Pikus, T. Polish. J. Chem. 1982, 56, 1297.

23. Jaxa-Chamiec, A.A.; Sammes, P.G.; Kennewell, P.D. J. Chem. Soc. Perkin. Trans. I 1980, 170.

24. Cass, Q.B.; Jaxa-Chamiec, A.A.; Sammes, P.G. J. Chem. Soc. Chem. Commun. 1981, 248.

25. Allmendinger, T. Tetrahedron 1991, 47, 4905.

26. Lee, K. Bull. Korean. Chem. Soc. 2011, 32, 3477.

27. Subramaniam, P.; Thamil Selvi, N. J. Serb. Chem. Soc. 2015, 80, 1019.

28. Subramaniam, P.; Thamil Selvi, N. Am. J. Anal. Chem. 2013, 4, 20.

29. Subramaniam, P.; Thamil Selvi, N.; Sugirtha Devi, S. J. Korean Chem. Soc. 2014, 58, 17.

30. Subramaniam, P.; Sugirtha Devi, S.; Anbarasan, S. J. Mol. Catal. A: Chem. 2014, 390, 159.

31. Subramaniam, P.; Thamil Selvi, N. Am. Chem. Sci. J. 2015, 6, 105.

32. Walker, D.; Leib, J. Can. J. Chem. 1962, 40, 1242.

33. Kenney, W.J.; Walsh, J.A.; Davenport, D.A. J. Am. Chem. Soc. 1961, 83, 4019.

34. Choudary, B.M.; Sreenivasa Chowdari, N.; Lakshmi Kantam, M. J. Chem. Soc., Perkin Trans. I 2000, 2689.

35. Robinson, E.A. Can. J. Chem. 1961, 39, 247.

36. Signorella, S.; Rizzotto, M.; Daier, V.; Franscaroli, M.I.; Palopoli, C.; Martino, D.; Boussekou, A.; Sala, L.F. J. Chem. Soc. Dalton. Trans. 1996, 1607.

37. Perez-Benito, J.F.; Arias, C. J. Phys. Chem. A. 1997, 101, 4726.

38. Palopoli, C.M.; Signorella, S.R.; Sala, L.F. New. J. Chem. 1997, 21, 343.

39. Adari, K.K.; Nowduri, A.; Parvataneni, V. Bull. Chem. Soc. Ethiop. 2008, 22, 305.

40. Krumpolc, M.; Rocek, J. J. Am. Chem. Soc. 1979, 101, 3206.

41. Wiberg, K.B. Oxidation in Organic Chemistry, Part A, Academic Press: New York; 1965.

42. Cainelli, G.; Cardillo, G. Chromium Oxidations in Organic Chemistry, Springer: Berlin; 1984.

43. Karunakaran, C.; Karuthapandian, S.; Suresh, S. Int. J. Chem. Kinet. 2003, 35, 1.

44. Chaubey, G.S.; Das, S.; Mahanti, M.K. Kinet. Catal. 2002, 43, 789.

45. Pitchumani, K.; Subramanian, V.; Jegatheesan, P.P.; Srinivasan, C. Proc. Indian. Acad. Sci. (Chem. Sci.) 1992, 104, 67.

46. Aruna, K.; Manikyamba, P. Int. J. Chem. Kinet. 1997, 29, 437.

47. Srinivasan, C.; Chellamani, A.; Rajagopal, S. J. Org. Chem. 1985, 50, 1201.

48. Levitt, L.S. J. Org. Chem. 1955, 20, 1297.

49. Peng, T.Y.; Rocek, J. J. Am. Chem. Soc. 1976, 98, 1026.

50. Roh, K.R.; Kim, K.S.; Kim, T.H. Tetrahedron. Lett. 1991, 32, 793.

51. Cooper, N.; Staudt, G.E.; Smalser, M.L.; Settzo, L.M.; Haight, G.P. Inorg. Chem. 1973, 12, 2075.

52. Perez-Benito, J.F.; Arias, C.; Lamrhari, D. J. Chem. Soc. Chem. Commun. 1992, 472. 